\title{
Characterization of the bacterial communities and iron corrosion scales in drinking groundwater distribution systems with chlorine/ chloramine
}

\author{
Xiaoxiao Li, Haibo Wang, Yu Zhang, Chun Hu*, Min Yang \\ Key Laboratory of Drinking Water Science and Technology, Research Center for Eco-Environmental Sciences, Chinese Academy of Sciences, Beijing 100085, \\ China
}

\section{A R T I C L E I N F O}

\section{Article history:}

Received 17 June 2014

Received in revised form

11 September 2014

Accepted 24 September 2014

Available online 6 November 2014

\section{Keywords:}

Biofilm

Corrosion

Groundwater

Drinking water

Pyrosequencing

\begin{abstract}
A B S T R A C T
The effect of chlorine and chloramine disinfection on bacterial communities and the corrosion of cast iron pipes was studied in drinking water distribution systems (DWDSs) transporting groundwater. $\alpha$ $\mathrm{FeOOH}$ was the main corrosion product for both systems. However, loose corrosion products were formed in DWDSs with chlorine, whereas dense crystallized particles were formed in DWDSs with chloramine. Based on the functional genes and pyrosequencing assay results, both DWDSs had different compositions of corrosion-related bacteria in the bulk water and biofilms. The percentage of total denitrifying gene copy numbers in the 16S rRNA and the bacterial diversities were much higher at $220 \mathrm{~d}$ within the bulk water and biofilm in DWDSs disinfected with chloramine compared with those disinfected with chlorine. Most of the $\mathrm{NO}_{3}^{-}-\mathrm{N}$ in the raw water was biologically denitrified through chlorine DWDSs in the experimental period, whereas the same phenomena occurred only when denitrifying bacteria were increased in the effluent due to the role of autotrophic microbial nitrification in chloramine DWDSs. Furthermore, nitrate-dependent Fe(II) oxidation occurred to a greater extent, leading to denser corrosion scales in DWDSs with chloramine compared with those disinfected with chlorine.
\end{abstract}

(๑) 2014 Elsevier Ltd. All rights reserved.

\section{Introduction}

Pipe corrosion, regrowth of bacteria and the formation of disinfectant byproducts may lead to water quality deterioration in drinking water distribution systems, which has been a challenge to water utilities.

Cast iron pipes have been used in drinking water distribution systems (DWDSs) for over 500 years. The corrosion of cast iron pipes is the most common distribution system problem. Corrosion scales are highly reactive species that can actively modify the physicochemical parameters of water in the distribution system not only by releasing $\mathrm{Fe}$ oxyhydroxides (red water) but also by reactions with chlorinated disinfection by-products (Chun et al., 2005), nitrates and/or with natural organic matter (NOM) (Nawrocki et al., 2010). Moreover, the interaction of corrosion scales with finished water can have adverse effects on the distribution water quality, possibly leading to the release of undesirable substances, which depend on the structure characteristics of the

\footnotetext{
* Corresponding author. Tel.: +86 10 62849628; fax: +861062923541.

E-mail address: huchun@rcees.ac.cn (C. Hu).
}

corrosion scales (Tang et al., 2006). The exact composition and structure of iron corrosion scales, however, varies significantly with the water quality and the hydraulic conditions. Numerous studies have indicated that alkalinity, $\mathrm{pH}$, and concentrations of chloride and sulfate are the primary water quality parameters affecting iron corrosion (Benson et al., 2012). Additionally, microbiologically influenced corrosion (MIC) affects diverse processes in DWDSs. For example, iron-precipitating bacteria (such as Gallionella) can convert $\mathrm{Fe}(\mathrm{II})$ to a $\mathrm{Fe}(\mathrm{III})$ and influence the $\mathrm{Fe}(\mathrm{III})$ precipitate structure (Volk et al., 2000). Anaerobic MIC of iron is the result of iron oxidation by a non-oxygen oxidant such as sulfate, nitrate and proton. Some nitrate- and $\mathrm{Fe}(\mathrm{III})$-reducing microorganisms are capable of oxidizing $\mathrm{Fe}(\mathrm{II})$ with nitrate as the electron acceptor (Coby et al., 2011; Xu et al., 2013). Sulfate-reducing bacteria (SRB), have also been reported to promote corrosion (Yuan et al., 2013), whereas iron-reducing bacteria (IRB) exhibited a protective effect in other studies (Dubiel et al., 2002). Recently an increasing number of studies have begun to show protective effects against corrosion by some bacterial biofilms on metal. Biofilms comprising ironrespiring bacteria, such as Bacillus infernos, Desulfovibrio profundus, and Geothrix fermentans, may reduce rather than accelerate the corrosion rate of steel (Herrera and Videla, 2009). Nitrate- 
reducing bacteria (NRB) will overcome SRB, because for a given electron donor, the energy gained from nitrate reduction is greater than the energy obtained from sulfate reduction. Elimination of SRB by NRB can inhibit hydrogen sulfide production and reduce the corrosion rate (Zarasvand and Rai, 2014). Additionally, microorganisms can also influence the biogeochemical cycling of iron by exuding chelating agents (siderophores) (Duckworth et al., 2009). Recently, we found that NRB could exhibit corrosion inhibition by inducing the redox cycling of iron to enhance the precipitation of iron oxides and formation of $\mathrm{Fe}_{3} \mathrm{O}_{4}$ in the AR with $\mathrm{UV} / \mathrm{Cl}_{2}$ (Zhu et al., 2014). Therefore, the corrosion process and corrosion products can be affected by the bacterial characteristics of waters and biofilms in DWDSs.

Chlorine disinfectants have been widely and effectively used to protect the safety of drinking water. Due to concerns over suspected carcinogens formed by chlorine use, water utilities are increasingly switching from chlorine to chloramine for residual disinfection (Zhang and Edwards, 2007). Chloramine is generally thought to produce a more stable residual than free chlorine and thus provides lasting protection against regrowth. In addition, chloramine is believed to penetrate more deeply than chlorine within the biofilm, thus providing greater inactivation (Zhang and DiGiano, 2002). Therefore, different bacterial community compositions in bulk water and biofilms would appear in DWDSs disinfected with chlorine and chloramine. However, to the best of our knowledge, no studies have compared the characterization of the bacterial communities and corrosion in the two DWDSs.

The objective of this study was to investigate the effects of chlorine and chloramine disinfection on the corrosion of cast-iron pipes and on the bacterial community structure of bulk water and biofilms in pilot DWDSs. The corrosion scales were characterized by X-ray powder diffraction (XRD), and scanning electron microscopy (SEM). Quantitative real-time PCR (qPCR) was used to monitor changes in the microbial abundance of the bulk water and biofilms inside corrosion scales according to specific groups: total bacteria by the $16 \mathrm{~S}$ rRNA gene and denitrifiers by the functional genes nosZ, nirK and nirS. Pyrosequencing was used to monitor the changes in the diversity of the microbial community. The relationship between corrosion and biofilms was discussed.

\section{Materials and methods}

\section{Pilot pipe distribution systems}

Experiments with free chlorine ( $\mathrm{CHL})$ and chloramine (CHM) as the disinfectant were conducted in parallel pilot-scale distribution systems using groundwater. The raw source was untreated groundwater prior to disinfection, and the water quality parameters are shown in Table 1. Each distribution system consisted of a $50-\mathrm{cm}$-long new cast iron pipe with a diameter of $10 \mathrm{~cm}$. The elemental composition (wt.\%) of the cast iron pipe was $\mathrm{C} 3.21 \%$, O

Table 1

Water quality of the raw water and effluents.

\begin{tabular}{llll}
\hline Parameters & Raw water & Effluents-chlorine & Effluents-chloramine \\
\hline $\mathrm{pH}$ & $7.60-8.06^{\mathrm{a}}$ & $8.20 \pm 0.38^{\mathrm{b}}$ & $7.99 \pm 0.13$ \\
$\mathrm{DO}\left(\mathrm{mg} \mathrm{L}^{-1}\right)$ & $7.35-7.46$ & $0.95 \pm 0.16$ & $1.47 \pm 0.28$ \\
$\mathrm{Cl}^{-}\left(\mathrm{mg} \mathrm{L}^{-1}\right)$ & $14.13-16.02$ & $31.45 \pm 2.80$ & $33.53 \pm 2.61$ \\
$\mathrm{SO}_{4}^{2-}\left(\mathrm{mg} \mathrm{L}^{-1}\right)$ & $21.41-24.85$ & $19.09 \pm 1.91$ & $19.61 \pm 1.73$ \\
$\mathrm{NO}_{3}^{-}\left(\mathrm{mg} \mathrm{L}^{-1}\right)$ & $22.30-34.93$ & - & - \\
$\mathrm{Alkalinity}\left(\mathrm{mg}^{\mathrm{c}} \mathrm{L}^{-1}\right)$ & $155-198$ & $118 \pm 7$ & $125 \pm 6$ \\
$\mathrm{LI}$ & $0.22-0.31$ & $0.61 \pm 0.15$ & $0.56 \pm 0.05$ \\
\hline
\end{tabular}

a value range.

b mean \pm standard deviation.

c $\mathrm{mg} \mathrm{CaCO}$.
1.63\%, Al 1.1\%, Si 1.85\%, and Fe 92.21\%. The pilot systems were operated with a two-day hydraulic retention time (HRT) to reflect dead zones or worst case conditions in an actual distribution system (Tang et al., 2006) in order to study the formation of corrosion scales and changes in biofilms. The disinfectant was mixed with the source water at a 1:10 volume before entering into the two DWDSs. Chlorine was dosed from a stock solution of sodium hypochlorite $(\mathrm{NaClO})$, whereas chloramine was added as a calculated amount of sodium hypochlorite solution and ammonium chloride with a $4: 1$ $\mathrm{Cl}_{2}: \mathrm{N}$ mass ratio.

\section{Physicochemical analysis}

The water quality parameters (Table 1), such as pH, alkalinity, ammonia nitrogen and chlorine concentration, were analyzed according to standard methods (EPA of China, 2002). Chloride $\left(\mathrm{Cl}^{-}\right)$, sulfate $\left(\mathrm{SO}_{4}^{2-}\right)$ and nitrate $\left(\mathrm{NO}_{3}^{-}\right)$were analyzed by ion chromatography (DIONEX ICS-2000). The dissolved oxygen (DO) was monitored with an Orion 4 Star meter (Thermo, USA). The LarsonSkold Index (LI) was calculated using the concentration of chlorides, sulfates and bicarbonates (Ishii and Boyer, 2011):

$\mathrm{LI}=\frac{\left[\mathrm{Cl}^{-}\right]+2\left[\mathrm{SO}_{4}^{2-}\right]}{\left[\mathrm{HCO}_{3}^{-}\right]}$.

Crystalline phase composition of corrosion scales was analyzed using an X-ray powder diffractometer (XRD, X'Pert PRO MPD; PANalytical, The Netherlands). The morphology of the corrosion products was examined by Field Emission Scanning Electron Microscopy (FESEM, Hitachi, SU8020). Differences among the experimental data were analyzed using analysis of variance (ANOVA) with a significance threshold of $\alpha=0.05$.

\section{Sampling and extraction of total DNA from water and biofilms}

For bulk water samples, bacteria from $3 \mathrm{~L}$ of each water sample were harvested by membrane filtration with $0.22-\mu \mathrm{m}$ Millipore GTTP filters and then transferred to sterile tubes for isolation. For corrosion scales with biofilms, samples were collected with a sterile metal spatula by scraping an approximately $3-\mathrm{cm}^{2}$ surface area from 6 different locations on each pipe. Then, those samples from the same pipe were mixed and lyophilized for further characterization.

The DNA was extracted from triplicate samples with the Fast DNA $^{\circledR}$ SPIN Kit for soil (MP Biomedicals, Solon, OH, USA) according to the manufacturer's instructions. The DNA quality was checked on an agarose gel, and the concentrations were measured with the NanoDrop (ND-1000, NanoDrop, USA). All DNA samples were stored at $-80{ }^{\circ} \mathrm{C}$ for future use.

\section{Quantitative PCR assay}

Perhaps 99\% of all organisms in environmental samples may be unable to be cultured, to quantify all bacteria and denitrifiers in the water and biofilm samples, quantitative PCR (qPCR) targeting the 16S rRNA, nirK, nirS and nosZ genes was performed. However, because PCR analyses are based on detection of intact nucleic acids rather than intact viable cells, there exists the possibility that positive pathogen PCR amplifications may arise from either dead cells or noninfectious cells. For all bacteria, the primer pair $1369 \mathrm{~F}$ and 1492R was combined with the probe TM1389F (Suzuki et al., 2000); for denitrifiers, nirK 876 and nirK 1040 (Henry et al., 2004), R3cd and cd3aF (Kandeler et al., 2006), and nosZ-F and 1622R (Throback et al., 2004) were used. The qPCR experiments 
were conducted with an Applied Biosystems 7300 qPCR system using premix Ex Taq ${ }^{\mathrm{TM}}$ or $\mathrm{SYBR}^{\circledR}$ premix Ex Taq ${ }^{\mathrm{TM}}$ (TaKaRa) in a 25$\mu \mathrm{L}$ reaction volume. The annealing temperatures were $60{ }^{\circ} \mathrm{C}$ for universal primer pairs, $55^{\circ} \mathrm{C}$ for nirK 876/nirK $1040,53^{\circ} \mathrm{C}$ for R3cd/ $\mathrm{cd} 3 \mathrm{aF}$ and $58{ }^{\circ} \mathrm{C}$ for nosZ-F/1622R, which were determined by gradient PCR to be the most suitable for the present samples. Plasmid standards and calibration curves were constructed according to Zhu et al. (2014). All samples, including standards and negative controls, were performed in triplicate. The $R^{2}$ and slopes of standard curves and amplification efficiency values for quantification were as follows: $0.995,-3.26$ and $102.4 \%$ for $16 \mathrm{~S}$ rRNA, $0.995,-3.45$ and $95.0 \%$ for nirK, $0.997,-3.28$ and $101.6 \%$ for nirS, $0.998,-3.36$ and $98.4 \%$ for nosZ, respectively.

\section{Pyrosequencing analysis}

The DNA was amplified with bacterium-specific forward primer $341 \mathrm{~F}$ (5'-Fusion A-Barcode-CA linker-CCTACGGGAGGCAGCAG-3') and reverse primer 1073R (5'-Fusion B-TC linker-ACGAGCTGACGACARCCATG-3') (Zhu et al., 2014). The PCR products of three independent reactions were pooled together, purified with an AxyPrep DNA Gel Extraction Kit (Axygen, USA), and quantified using a TBS-380 Fluorometer (Turner Biosystems, USA). Before pyrosequencing, the PCR products from different samples were normalized to equimolar amounts in the final mixture, which was used to construct PCR amplicon libraries. The pyrosequencing was performed on a Roche massively parallel 454 GS-FLX Titanium
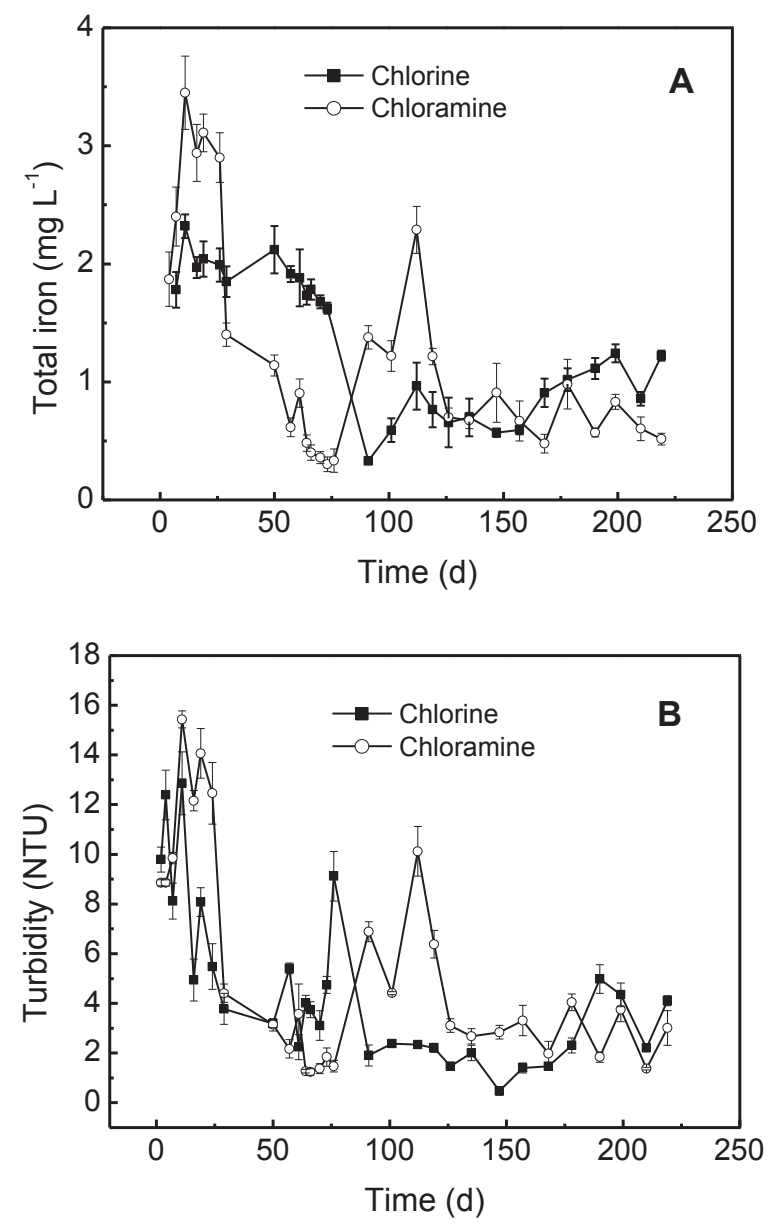

Fig. 1. Change in the total iron (A) and turbidity (B) of the effluents from the chlorine and chloramine DWDSs. The error bars represent one standard deviation. sequencer (Roche 454 Life Sciences, Branford, CT, USA) according to standard protocols. The pyrosequencing flowgrams were converted to sequence reads using the MOTHUR software (http://www. mothur.org/) and then analyzed using the UCHIME (http://drive5. com/uchime) standard pipeline. The sequence reads were initially filtered and denoised to remove low-quality or ambiguous reads. High-quality sequences ( $>200$ bp in length, quality score $>25$, exact match to barcode and primer, and containing no ambiguous characters) remained with an average length of $436 \mathrm{bp}$. The total bacterial communities were analyzed for the number of operational taxonomic units (OTUs) and species richness using the Mothur program. The numbers of OTUs were estimated at 97\% 16S rRNA gene sequence similarity. The taxonomic positions of representative sequences were assigned using the SILVA database (http:// www.arb-silva.de/).

\section{Results}

Water quality change in DWDSs with chlorine and chloramine

The initial total chlorine dose was approximately $10 \mathrm{mg} \mathrm{Cl}_{2} \mathrm{~L}^{-1}$ in the two DWDSs disinfected with chlorine and chloramine. No significant difference was observed in the initial chlorine $(p=0.29)$ between the two DWDSs by ANOVA analysis. The total iron concentration of effluents in DWDS-GW was $1.78 \mathrm{mg} \mathrm{L}^{-1}$ at $7 \mathrm{~d}$, and increased to $2.32 \mathrm{mg} \mathrm{L}^{-1}$ at $11 \mathrm{~d}$. After that, it gradually decreased to $1.62 \mathrm{mg} \mathrm{L}^{-1}$ at $73 \mathrm{~d}$ except a little fluctuation at $50 \mathrm{~d}$, and then quickly decreased to $0.33 \mathrm{mg} \mathrm{L}^{-1}$ at $91 \mathrm{~d}$, and after this point, it gradually stabilized at approximately $0.86 \mathrm{mg} \mathrm{L}^{-1}$ (Fig. 1A). In the DWDSs with chloramine, the total iron concentration decreased
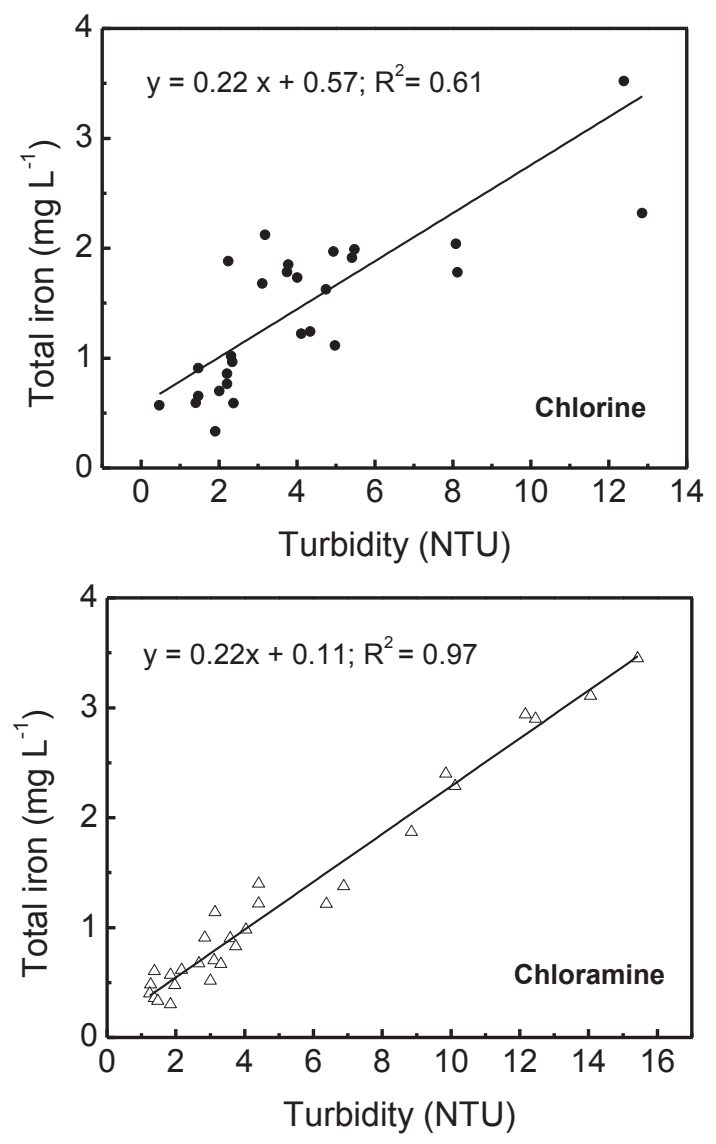

Fig. 2. Total iron versus turbidity of the effluents from the chlorine and chloramine DWDSs. 
from $3.45 \mathrm{mg} \mathrm{L}^{-1}$ at the beginning of the experiment to $0.33 \mathrm{mg} \mathrm{L}^{-1}$ at $75 \mathrm{~d}$, increased again to $2.29 \mathrm{mg} \mathrm{L}^{-1}$, decreased to $0.70 \mathrm{mg} \mathrm{L}^{-1}$ at $126 \mathrm{~d}$, and then stabilized at approximately $0.69 \mathrm{mg} \mathrm{L}^{-1}$ (Fig. 1A). Additionally, iron concentration of the effluent in the chloramine DWDSs was significantly higher than that in chlorine DWDSs ( $p=0.019$ ) before $26 \mathrm{~d}$, but it showed an opposite tendency in the period of 29 to $76 \mathrm{~d}(p<0.01)$. After $91 \mathrm{~d}$, the two DWDSs exhibited similar iron concentrations in the effluents $(p=0.47)$. A similar result can be observed in the turbidity value, with stabilization at approximately $125 \mathrm{~d}$ in the two DWDSs (Fig. 1B). However, a better linear correlation was observed between the total iron concentration and the turbidity of the effluents in the chloramine disinfection $\left(R^{2}=0.97\right)$ compared with the chlorine disinfection $\left(R^{2}=0.61\right)$ (Fig. 2). In the corrosion processes of iron pipes, iron ions were released into the distributed water and could re-precipitate, forming corrosion scales (Mutoti et al., 2007). The processes can greatly affect the correlation of the total iron concentration and turbidity of the effluents, suggesting possibly different precipitation and dissolution properties of the corrosion scales formed in the two systems. In the effluents, except for the $\mathrm{pH}$ and $\mathrm{SO}_{4}^{2-}$ concentration, the water parameters showed significant changes. The DO decreased to approximately $1 \mathrm{mg} \mathrm{L}^{-1}$ in the two DWDSs. The alkalinity decreased to $118 \mathrm{mg} \mathrm{L}^{-1}(p<0.05)$ and $125 \mathrm{mg} \mathrm{L}^{-1}$ $(p<0.05)$ in the chlorine and chloramine DWDSs, respectively. Accordingly, LI index increased to approximately 0.60 in these two DWDSs.

In addition, the two DWDSs exhibited different changes in nitrate removal with increasing time (Fig. 3). In the chlorine DWDSs, the $\mathrm{NO}_{3}^{-}-\mathrm{N}$ removal greatly increased to $3.53 \mathrm{mg} \mathrm{L}^{-1}$ before $64 \mathrm{~d}$, then gradually increased to $5.55 \mathrm{mg} \mathrm{L}^{-1}$ at $135 \mathrm{~d}$, and tended to
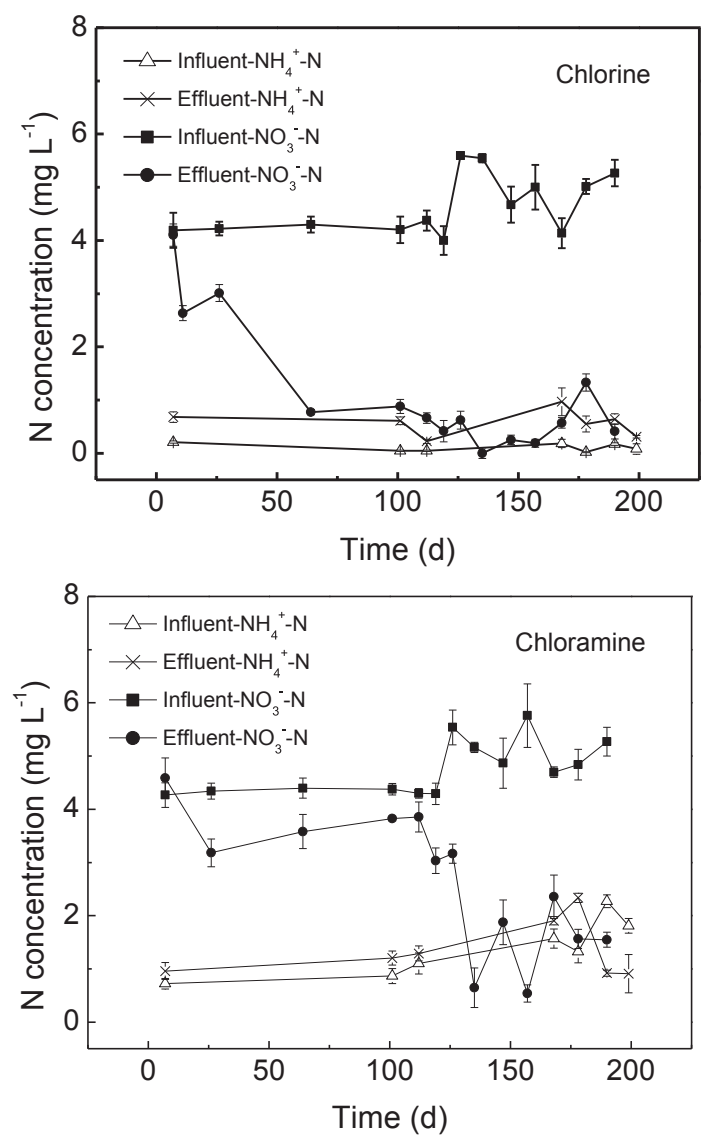

Fig. 3. Change in the nitrate and ammonium of the influents and effluents in the chlorine and chloramine DWDSs. The error bars represent one standard deviation. stabilize at a value of $4.28 \mathrm{mg} \mathrm{L}^{-1}$, whereas $\mathrm{NH}_{4}^{+}-\mathrm{N}$ increased to a maximum of approximately $0.78 \mathrm{mg} \mathrm{L}^{-1}$ throughout the experimental time, indicating that most of the nitrate was not transformed to ammonium. In addition, no significant nitrite was observed during this period. The results suggested that most of the nitrate was biologically denitrified to $\mathrm{N}_{2}$ and not converted to ammonia by the reduction of zero-valent iron (Westerhoff and James, 2003; Shapleigh, 2013). In the chloramine DWDSs, the decrease in both the $\mathrm{NO}_{3}^{-}-\mathrm{N}$ and $\mathrm{NH}_{4}^{+}-\mathrm{N}$ concentration did not exhibit significant changes in the effluents before $120 \mathrm{~d}$, and the removal rate of $\mathrm{NO}_{3}^{-}-\mathrm{N}$ was much less than that found in the DWDSs with chlorine, indicating that both denitrification and nitrification reactions occurred in the DWDSs (Nawrocki et al., 2010). However, after $120 \mathrm{~d}$, the $\mathrm{NO}_{3}^{-}-\mathrm{N}$ removal greatly increased to approximately $5.22 \mathrm{mg} \mathrm{L}^{-1}$ at $157 \mathrm{~d}$ and then greatly decreased to $3.72 \mathrm{mg} \mathrm{L}^{-1}$ at $190 \mathrm{~d}$. Correspondingly, at this time point, the $\mathrm{NH}_{4}^{+}-\mathrm{N}$ removal in the effluents significantly increased to $1.35 \mathrm{mg} \mathrm{L}^{-1}$, which is equal to the decrease in $\mathrm{NO}_{3}^{-}-\mathrm{N}$ removal. The results also indicated that most of the nitrate was removed by biological denitrification after $190 \mathrm{~d}$ in the DWDSs with chloramine.

\section{Characterization of corrosion scales}

The two DWDSs exhibited the predominant crystalline corrosion product of goethite ( $\alpha$-FeOOH) (Fig. 4). Their peak intensities increased with increasing exposure, and the peak was sharper in the DWDSs with chloramine than that with chlorine, indicating greater crystallization. The SEM micrographs of different corrosion
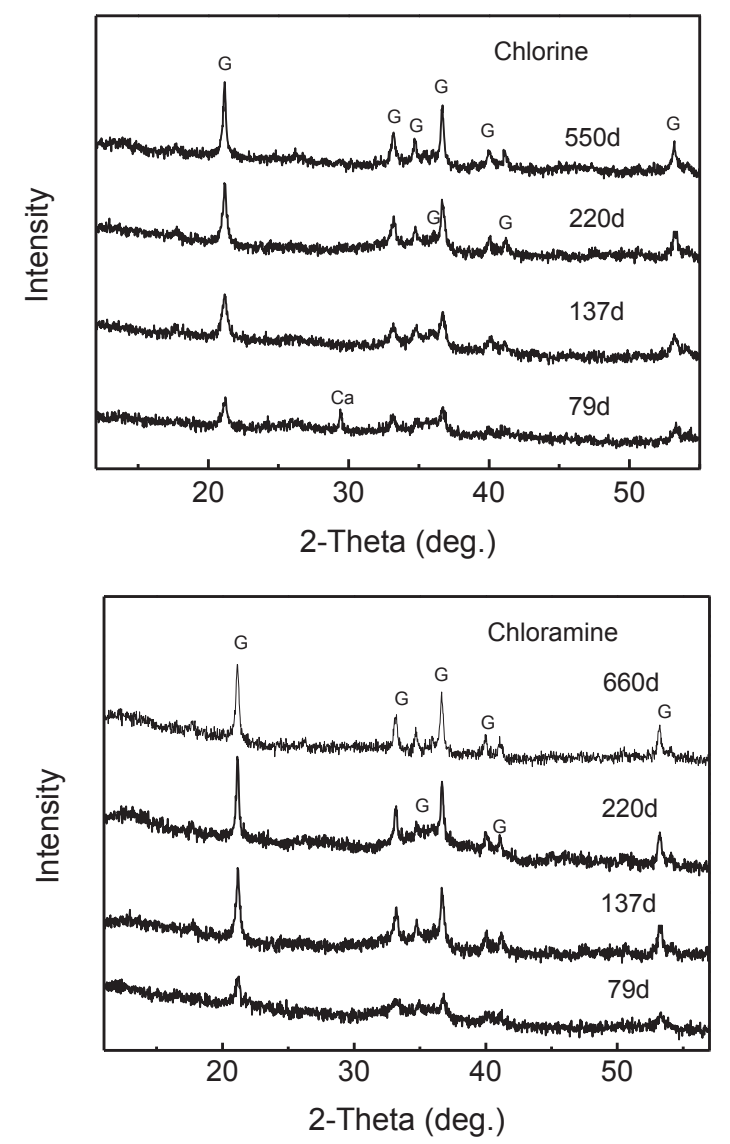

Fig. 4. XRD patterns of the corrosion scales in the chlorine and chloramine DWDSs (Ggoethite; Ca-Calcite). 
scales are shown in Figs. 5 and 6. Loosely amorphous corrosion scales appeared before $137 \mathrm{~d}$, and filaments of $\alpha$-FeOOH formed at $220 \mathrm{~d}$ in the DWDSs with chlorine (Fig. 5). In the chloramine pipe, well-crystallized particles were observed at $79 \mathrm{~d}$, indicating the formation of a dense oxide layer, whereas more densely crystallized particles appeared at 137 and $220 \mathrm{~d}$ (Fig. 6). The results indicated that the iron produced by corrosion can be re-precipitated to form corrosion scales more easily in the DWDSs with chloramine than that with chlorine, which contributed to the better correlation of the total iron concentration and turbidity.

The abundance of denitrifying functional genes in the bulk water and biofilms

Both the reduction of nitrate and iron redox cycling were induced by the respiration of some denitrifying bacteria (Weber et al., 2006a). Therefore, denitrifying functional genes were analyzed quantitatively by qPCR. Figs. 7 and 8 show the nirS, nirK, nosZ, and 16S rRNA gene copy numbers of the bulk water and biofilms in the two DWDSs. The 16S rRNA gene copy number was $2.02 \times 10^{7}$ copies $\mathrm{mL}^{-1}$ in raw water, and it increased to some extent in the effluents of DWDSs with chlorine and chloramine, indicating an increase in the microbial biomass (Fig. 7A). Although the three denitrifying functional gene copy numbers of the bulk water greatly increased with increasing 16S rRNA gene numbers, they exhibited different changes in the two DWDSs. The percentage of total denitrifying gene numbers in 16S rRNA greatly increased from $0.73 \%$ in raw water to approximately $9.03 \%$ at $137 \mathrm{~d}$ and $8.11 \%$ at $220 \mathrm{~d}$ in the effluents of DWDS with chlorine, whereas it increased to $6.43 \%$ at $137 \mathrm{~d}$ and $11.11 \%$ at $220 \mathrm{~d}$ in the effluent with chloramine (Fig. 7B). Correspondingly, for the biofilm samples (Fig. 8A), the $\operatorname{nirS}(p<0.01)$, $\operatorname{nirK}(p<0.01)$, and 16S rRNA $(p<0.01)$ gene copy numbers were much higher in the DWDSs with chloramine than that with chlorine. In addition, the percentage of denitrifiers of the total bacteria was $17.87 \%$ at $137 \mathrm{~d}$ and $9.08 \%$ at $220 \mathrm{~d}$ in the DWDSs with chloramine, which is much higher than that obtained with chlorine (Fig. 8B).

Bacterial community composition of the bulk water and biofilms of corrosion scales

Pyrosequencing yielded a total of 28,545 high-quality sequences for the 16S rRNA gene for all samples, with OTUs from 443 to 784 (Table 2). Good's coverage revealed that these libraries represented the majority of the bacterial 16S rRNA sequences present in each sample, with values ranging from 92\% to 96\%. Moreover, the Shannon index was 4.79 for raw water and 2.62 and 4.38 in the effluents of the DWDSs with chlorine and chloramine, respectively. The results indicated that disinfection inhibited the bacterial activity in the DWDSs, and chlorine exhibited more bactericidal potency than chloramine. Similarly, the biofilm in the DWDSs with chlorine had a lower Shannon index, indicating the lower bacterial diversity within the biofilm in these DWDSs than in the DWDSs with chloramine.

Four major phyla ( $>3 \%$ in total sequences), namely Proteobacteria, Bacteroidetes, Acidobacteria and Actinobacteria, appeared in all of the samples (Table 3). Among them, Proteobacteria predominantly contained Alphaproteobacteria, Betaproteobacteria and Gammaproteobacteria, whereas Sphingobacteria was dominant in the phylum Bacteroidetes, and Actinobacteria was dominant in the phylum Actinobacteria. In raw water, the major phyla were Proteobacteria (64.0\%), Bacteroidetes (26.9\%) and Actinobacteria (4.5\%), whereas Proteobacteria (97\%) and Bacteroidetes (2.4\%) appeared in the effluent with chlorine, and Proteobacteria (90.7\%) and Bacteroidetes (6.0\%) appeared in the effluent with chloramine. Moreover, Proteobacteria and Bacteroidetes were the major groups in the biofilms of the two DWDSs, although they exhibited different percentages. Acidobacteria (13.4\%) appeared in the chlorine system. The results indicated that the bacterial community structure of the
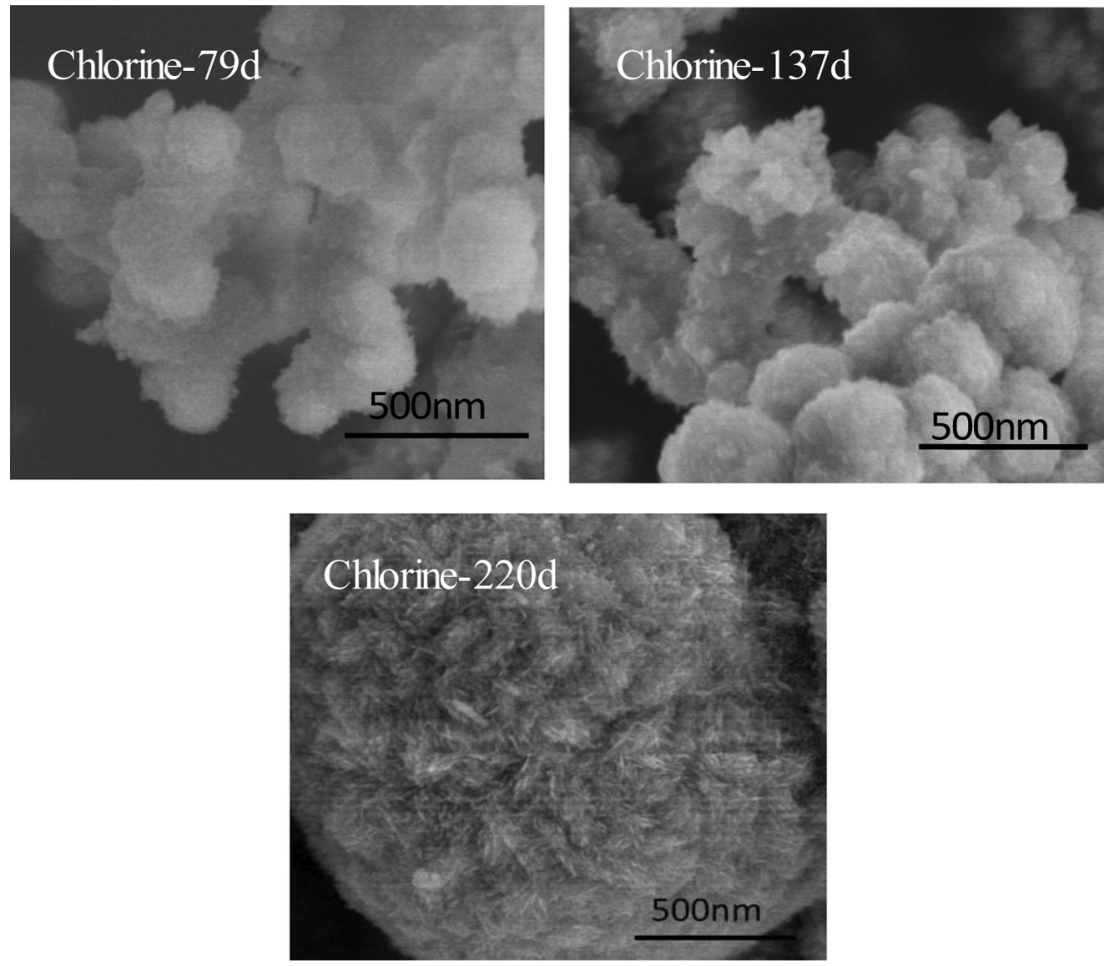

Fig. 5. SEM micrographs of the corrosion scales in the chlorine DWDSs for different amounts of time. 

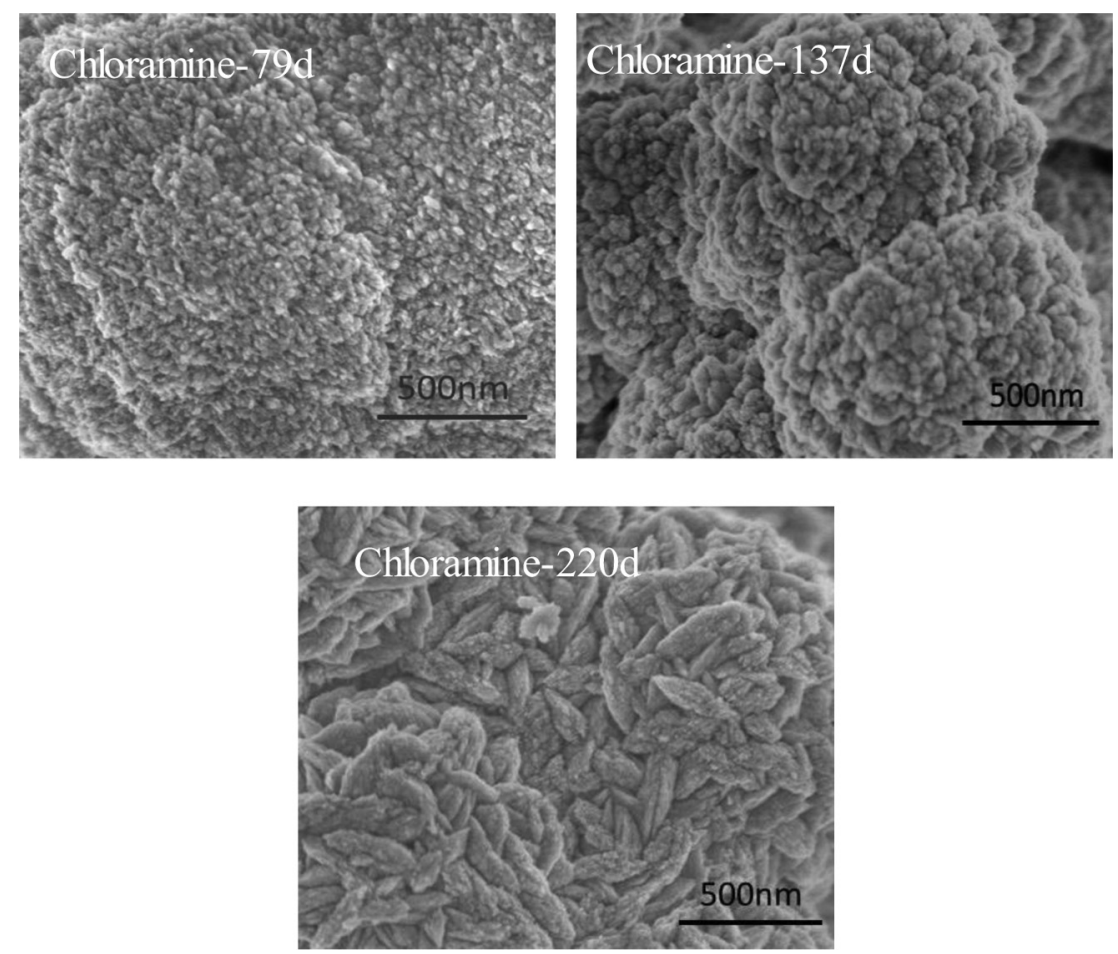

Fig. 6. SEM micrographs of the corrosion scales in the chloramine DWDSs for different amounts of time.
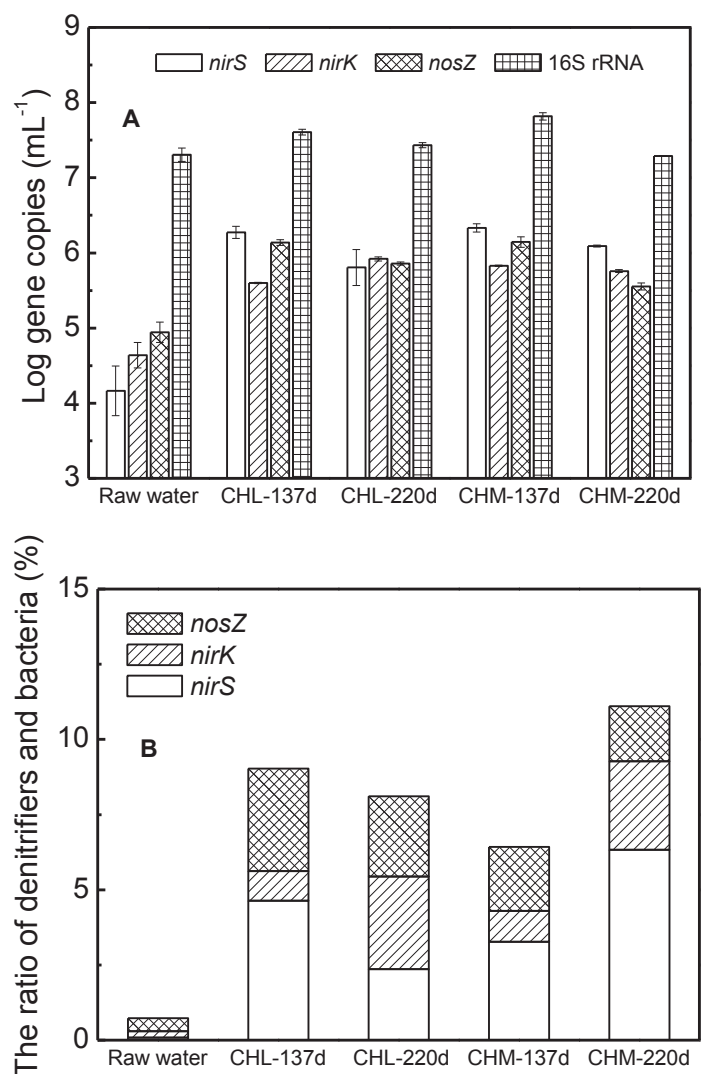

Fig. 7. The abundance of the bacterial nirS, nirK, nosZ, and $16 \mathrm{~S}$ rRNA genes (A) and the relative abundance of selected genes normalized to the 16S rRNA in bulk water (B) from the chlorine (CHL) and chloramine (CHM) DWDSs. The error bars represent one standard deviation.
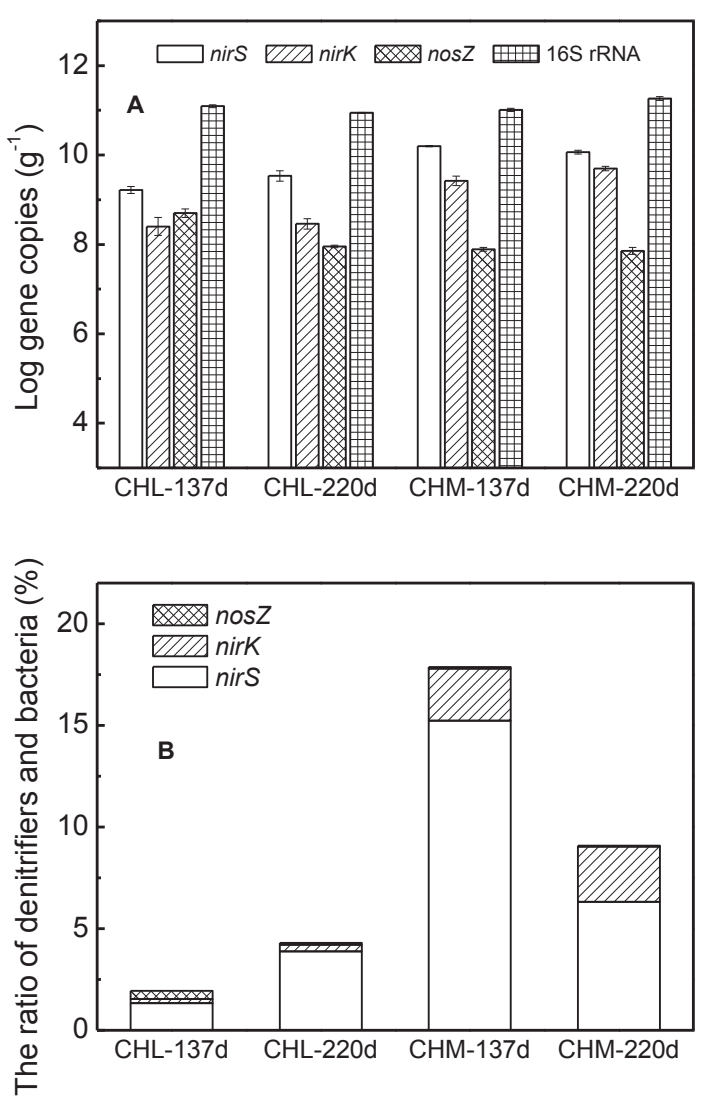

Fig. 8. The abundance of the bacterial nirS, nirK, nosZ, and 16S rRNA genes (A) and the relative abundance of selected genes normalized to the 16S rRNA in biofilm samples (B) from the chlorine (CHL) and chloramine (CHM) DWDSs. The error bars represent one standard deviation. 
Table 2

Coverage and diversity index of the bacterial 16S rRNA gene libraries of the bulk water and biofilm samples $(\alpha=0.03)$.

\begin{tabular}{lllll}
\hline Sample & Reads & Coverage & OTUs & Shannon \\
\hline Raw water & 5476 & $92 \%$ & 784 & 4.79 \\
Effluent-CHL & 6416 & $96 \%$ & 443 & 2.62 \\
Effluent-CHM & 5175 & $93 \%$ & 667 & 4.38 \\
Biofilm-CHL & 6305 & $95 \%$ & 620 & 4.14 \\
Biofilm-CHM & 5173 & $92 \%$ & 760 & 4.58 \\
\hline
\end{tabular}

bulk water had a significant influence on the composition of the biofilms.

Fig. 9 shows the taxonomic breakdown at the class level $(>1 \%)$ for the bulk water and biofilms of the corrosion scales. In raw water, the major classes were Alphaproteobacteria (25.4\%), Gammaproteobacteria (23.2\%), and Sphingobacteria (20.2\%), and the minor classes were Betaproteobacteria (6.6\%), Actinobacteria (3.5\%), and Acidobacteria (1.0\%). In the effluent at $220 \mathrm{~d}$ with chlorine, Alphaproteobacteria (86.7\%) was the most abundant class, Betaproteobacteria increased to $10.6 \%$, Sphingobacteria decreased to $2.4 \%$, and Gammaproteobacteria and the other bacteria disappeared. Correspondingly, Betaproteobacteria (40.2\%), Alphaproteobacteria (12.9\%), Sphingobacteria (30.2\%), Holophagae (13.4\%) and Gemmatimonadetes (2.9\%) appeared in the biofilm. In the effluent at $220 \mathrm{~d}$ with chloramine, Alphaproteobacteria (46.1\%) and Betaproteobacteria (44.4\%) were the dominant classes, whereas Sphingobacteria decreased to $6 \%$ and Gammaproteobacteria decreased to $0.14 \%$. In the biofilm, Betaproteobacteria (35.7\%), Alphaproteobacteria (22.4\%) and Sphingobacteria (34.8\%) were the predominant classes.

The pyrosequencing of all samples revealed that Betaproteobacteria, Alphaproteobacteria and Sphingobacteria were the predominant classes in the bulk water and biofilms in the DWDSs with chlorine and chloramine. Both systems had similar classes, although their relative abundances were different.

The compositions of the corrosion-related bacteria underwent significant changes in the bulk water and biofilms in the DWDSs (Fig. 10). In raw water, the dominant bacteria was the iron-oxidizing bacteria Sediminibacterium (19.2\%) (Wang et al., 2012), and other iron-respiring bacteria and nitrate-reducing bacteria were found at levels below $0.8 \%$. In the effluent of the DWDS with chlorine, nitrate-reducing bacteria associated with the redox cycling of iron (NRB-Fe) were found at 5.8\%, and these included Zoogloea $(2.75 \%)$ (Sag and Kutsal, 1995; Shapleigh, 2013), Aquabacterium (1.54\%) (Straub et al., 2004), Azospira (0.63\%) (Byrne-Bailey and Coates, 2012) and Dechloromonas (0.42\%) (Weber et al., 2006b), as well as some genera at levels less than $0.3 \%$. The percentage of Sediminibacterium decreased to $2.54 \%$. In addition, the NRB-producing siderophore (NRB-S) Sphingomonas (Duckworth et al., 2009) increased to $2.6 \%$. In the biofilm of the DWDS with chlorine, IOB Sediminibacterium was 30.1\%, and IRB Geothrix (Nevin and Lovley, 2002) was $12.4 \%$, whereas NRB-Fe was nearly $20 \%$ and mainly

Table 3

Taxonomic classification of the phylogenetic groups (>3\%) from the bulk water and biofilm samples at the phylum level in the chlorine (CHL) and chloramine (CHM) DWDSs.

\begin{tabular}{lrrrrr}
\hline \multicolumn{5}{l}{ Percentage of sequence (\%) } \\
\cline { 2 - 6 } & $\begin{array}{l}\text { Raw } \\
\text { water }\end{array}$ & Effluent-CHL & Effluent-CHM & Biofilm-CHL & Biofilm-CHM \\
\hline Acidobacteria & 1.0 & 0.2 & 0.04 & 13.4 & 1.1 \\
Actinobacteria & 4.5 & 0.0 & 0.06 & 0.0 & 0.9 \\
Bacteroidetes & 26.9 & 2.4 & 6.0 & 30.2 & 34.8 \\
Proteobacteria & 64.0 & 97.4 & 90.7 & 53.5 & 61.0 \\
\hline
\end{tabular}

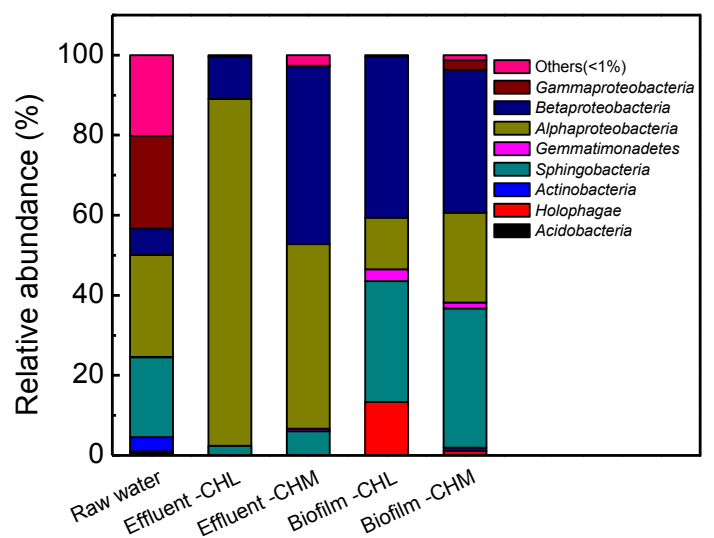

Fig. 9. Taxonomic assignment of the $16 \mathrm{~S}$ rRNA gene sequences retrieved from the bulk water and biofilm samples classified by class in the chlorine $(\mathrm{CHL})$ and chloramine (CHM) DWDSs.

included Azospira (9.6\%), Dechloromonas (6\%), and Zoogloea (3.6\%). The siderophore-producing Bradyrhizobium (Arif et al., 2012) was 4.99\%. In the effluent with chloramine, IOB Sediminibacterium was 5.7\%, NRB-Fe were 24.3\% and included Azospira (11.2\%), Dechloromonas (8.9\%), Zoogloea (3.8\%) and several other genera at levels less than $0.2 \%$. For the biofilm sample from the chloramine DWDS, IOB Sediminibacterium was $34.5 \%$. NRB-Fe was $19.4 \%$ and mainly included Azospira (7.2\%), Dechloromonas (5.9\%), and Rhodopseudomonas (5.6\%) (Shapleigh, 2013). NRB-S Bradyrhizobium was $1.3 \%$, and Sphingomonas was $1.5 \%$. The relative abundances of NRBFe in the effluent with chloramine were much higher than that in the effluent with chlorine; however, their relative abundances were approximate in the biofilms.

\section{Discussion}

In general, the total iron concentration in bulk water depended on corrosion and dissolution of corrosion scales (Mutoti et al., 2007). At the initial stage, the total iron in bulk water predominantly came from iron corrosion. Therefore, the iron release results indicated that the corrosion rate was higher with chloramine than with chlorine before $26 \mathrm{~d}$. After this, the total iron concentration greatly decreased in DWDSs with chloramine, indicating that iron corrosion was inhibited by the dense oxide layer, while the loosely amorphous corrosion scales led to higher iron release from 29 to $76 \mathrm{~d}$ in DWDSs with chlorine. The processes of the transformation

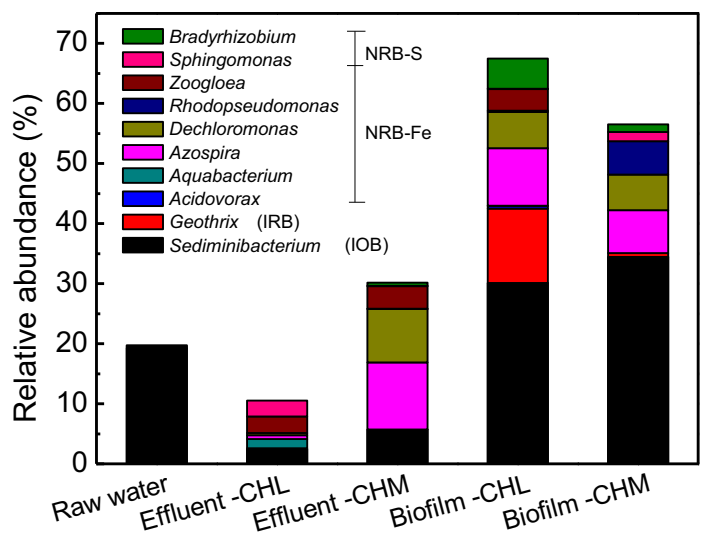

Fig. 10. Relative abundance of the corrosion-related bacteria genera $(>1 \%)$ of the bulk water and biofilm samples from the chlorine ( $\mathrm{CHL}$ ) and chloramine (CHM) DWDSs. 
of $\mathrm{NO}_{3}^{-}-\mathrm{N}$ were different between the chlorine and chloramine DWDSs. Throughout the experiments, most of the $\mathrm{NO}_{3}^{-}-\mathrm{N}$ was biologically denitrified to $\mathrm{N}_{2}$ in the chlorine DWDSs. In the chloramine DWDSs, no significant $\mathrm{NO}_{3}^{-}-\mathrm{N}$ was transformed until $120 \mathrm{~d}$. Neither the $\mathrm{NO}_{3}^{-}-\mathrm{N}$ nor the $\mathrm{NH}_{4}^{+}-\mathrm{N}$ concentrations exhibited significant changes in the effluents, indicating that the denitrifying transformation of $\mathrm{NO}_{3}^{-}-\mathrm{N}$ was offset by autotrophic microbial nitrification because the ammonia arising from chloramine decay can support autotrophic microbial nitrification (Zhang et al., 2008). After $120 \mathrm{~d}$, most of $\mathrm{NO}_{3}^{-}-\mathrm{N}$ was converted to $\mathrm{N}_{2}$ by microbial denitrification (Shapleigh, 2013), indicating that more denitrifying bacteria appeared in the chloramine DWDSs. In the effluent and biofilm of the chloramine DWDSs at $220 \mathrm{~d}$, the percentage of denitrifiers of the total bacteria was much higher than that obtained in the chlorine DWDSs. It has been reported that the oxidation and reduction of iron is induced by the respiration of some denitrifying bacteria (Weber et al., 2006a). The nitrate-dependent Fe(II) oxidation was observed in corrosion scales with biofilms from both DWDSs in the presence of $\mathrm{NO}_{3}^{-}-\mathrm{N}$. The result confirmed that nitrate-dependent $\mathrm{Fe}(\mathrm{II})$ oxidation occurred predominantly with the denitrification of $\mathrm{NO}_{3}^{-}-\mathrm{N}$ by NRB-Fe and IRB in both systems. The NRB-Fe (24.3\%) was much higher in the effluent of DWDSs with chloramine than that with chlorine (5.8\%), leading to a greater occurrence of nitrate-dependent $\mathrm{Fe}(\mathrm{II})$ oxidation in the DWDSs with chloramine. The microbial oxidation of Fe(II) enhanced the precipitation of the released iron from the iron pipe corrosion, leading to iron ions mostly in the particle form. Therefore, the iron release and turbidity of the effluents exhibited better linear correlation in the chloramine DWDSs. The enhanced precipitation of iron ions by microorganisms led to the formation of denser corrosion scales in the chloramine DWDSs.

\section{Conclusions}

The results showed that most of the $\mathrm{NO}_{3}^{-}-\mathrm{N}$ in raw water was biologically denitrified through chlorine DWDSs from beginning to $220 \mathrm{~d}$, whereas the same phenomena did not occur in the chloramine DWDSs until $120 \mathrm{~d}$. $\mathrm{NO}_{3}^{-}-\mathrm{N}$ was largely converted when the percentage of denitrifying bacteria increased in the effluent. The results indicated that autotrophic microbial nitrification occurred due to the presence of ammonia arising from chloramine decay in the chloramine DWDSs. The percentage of total denitrifying gene copy numbers in the 16S rRNA and the bacterial diversities were much higher within the bulk water and biofilms in the DWDSs with chloramine than in that with chlorine at $220 \mathrm{~d}$. Correspondingly, both DWDSs had different compositions of corrosion-related bacteria in the bulk water and biofilms. In the chlorine DWDSs, the corrosion-related bacteria included NRB-Fe (5.8\%) and IOB Sediminibacterium $(2.5 \%)$ in the effluent, whereas it predominantly included IOB Sediminibacterium (30.1\%), IRB Geothrix (12.4\%) and NRB-Fe $(20 \%)$ in the biofilm. In the chloramine DWDSs, the corrosion-related bacteria were NRB-Fe $(24.3 \%)$ and IOB Sediminibacterium (5.7\%) in the effluent, whereas IOB Sediminibacterium (34.5\%) and NRB-Fe (19.4\%) were dominant in the biofilm. Furthermore, nitrate-dependent Fe(II) oxidation occurred to a greater extent, leading to denser corrosion scales in the DWDSs with chloramine than in that with chlorine.

\section{Acknowledgments}

This work was funded by grants from the National Natural Science Foundation of China (Nos. 51308529, 21125731, 51290281 and 51221892), the Federal Department of Chinese Water Control and Treatment (No. 2012ZX07404002) and the project of RCEES (YSW2013A02).

\section{References}

Arif, K., Archana, G., Anjana, D.J., 2012. Engineering heterologous iron siderophore complex utilization in rhizobia: effect on growth of peanut and pigeon pea plants. Appl. Soil Ecol. 53, 65-73.

Benson, A.S., Dietrich, A.M., Gallagher, D.L., 2012. Evaluation of iron release models for water distribution systems. Crit. Rev. Environ. Sci. Technol. 42, 44-97.

Byrne-Bailey, K.G., Coates, J.D., 2012. Complete genome sequence of the anaerobic perchlorate-reducing bacterium Azospira suillum strain PS. J. Bacteriol. 194, 2767.

Chun, C.L., Hozalski, R.M., Arnold, W.A., 2005. Degradation of drinking water disinfection byproducts by synthetic goethite and magnetite. Environ. Sci. Technol. 39, 8525-8532.

Coby, A.J., Picardal, F., Shelobolina, E., Xu, H.F., Roden, E.E., 2011. Repeated anaerobic microbial redox cycling of iron. Appl. Environ. Microbiol. 77, 6036-6042.

Dubiel, M., Hsh, C.H., Chien, C.C., Mansfeld, F., Newman, D.K., 2002. Microbial iron respiration can protect steel from corrosion. Appl. Environ. Microbiol. 68 $1440-1445$.

Duckworth, O.W., Holmstrom, S.J.M., Pena, J., Sposito, G., 2009. Biogeochemistry of iron oxidation in a circumneutral freshwater habitat. Chem. Geol. 260, 149-158.

EPA of China, 2002. Analysis Method for Water and Waste Water, fourth ed. Press of Chinese Environmental Science, Beijing.

Henry, S., Baudouin, E., Lopez-Gutierrez, J.C., Martin-Laurent, F., Brauman, A., Philippot, L., 2004. Quantification of denitrifying bacteria in soils by nirK gene targeted real-time PCR. J. Microbiol. Methods 59, 327-335.

Herrera, L.K., Videla, H.A., 2009. Role of iron-reducing bacteria in corrosion and protection of carbon steel. Int. Biodeterior. Biodegrad. 63, 891-905.

Ishii, S.K.L., Boyer, T.H., 2011. Evaluating the secondary effects of magnetic ion exchange: focus on corrosion potential in the distribution system. Desalination $274,31-38$.

Kandeler, E., Deiglmayr, K., Tscherko, D., Bru, D., Philippot, L., 2006. Abundance of narG, nirS, nirk, and nosZ genes of denitrifying bacteria during primary successions of a glacier foreland. Appl. Environ. Microbiol. 72, 5957-5962.

Mutoti, G., Dietz, J.D., Imran, S.A., Taylor, J., Cooper, C.D., 2007. Development of a novel iron release flux model for distribution systems. J. Am. Water Works Assoc. 99, 102-111.

Nawrocki, J., Raczyk-Stanislawiak, U., Swietlik, J., Olejnik, A., Sroka, M.J., 2010. Corrosion in a distribution system: steady water and its composition. Water Res. 44, 1863-1872.

Nevin, K.P., Lovley, D.R., 2002. Mechanisms for accessing insoluble Fe(III) oxide during dissimilatory Fe(III) reduction by Geothrix fermentans. Appl. Environ. Microbiol. 68, 2294-2299.

Sag, Y., Kutsal, T., 1995. Biosorption of heavy metals by Zoogloea ramigera: use of adsorption isotherms and a comparison of biosorption characteristics. Chem. Eng. J. 60, 181-188.

Shapleigh, J.P., 2013. Denitrifying prokaryotes. In: Rosenberg, E., DeLong, E.F., Lory, S., Stackebrandt, E., Thonmpson, F. (Eds.), The Prokaryotes-prokaryotic Physiology and Biochemistry, fourth ed. Springer-Verlag Berlin, Heidelberg, pp. 405-421.

Straub, K.L., Schonhuber, W.A., Buchholz-Cleven, B.E.E., Schink, B., 2004. Diversity of ferrous iron-oxidizing, nitrate-reducing bacteria and their involvement in oxygen-independent iron cycling. Geomicrobiol. J. 21, 371-378.

Suzuki, M.T., Taylor, L.T., DeLong, E.F., 2000. Quantitative analysis of small-subunit rRNA genes in mixed microbial populations via 5'-nuclease assays. Appl. Environ. Microbiol. 66, 4605-4614.

Tang, Z.J., Hong, S.K., Xiao, W.Z., Taylor, J., 2006. Characteristics of iron corrosion scales established under blending of ground, surface, and saline waters and their impacts on iron release in the pipe distribution system. Corros. Sci. 48, $322-342$.

Throback, I.N., Enwall, K. Jarvis, A., Halli, S., 2004. Reassessing PCR primers targeting nirS, nirK and nosZ genes for community surveys of denitrifying bacteria with DGGE. FEMS Microbiol. Ecol. 49, 401-417.

Volk, C., Dundore, E., Schiermann, J., Lechevallier, M., 2000. Practical evaluation of iron corrosion control in a drinking water distribution system. Water Res. 34 1967-1974.

Wang, H.B., Hu, C., Hu, X.X., Yang, M., Qu, J.H., 2012. Effects of disinfectant and biofilm on the corrosion of cast iron pipes in a reclaimed water distribution system. Water Res. 46, 1070-1078.

Weber, K.A., Achenbach, L.A., Coates, J.D., 2006a. Microorganisms pumping iron: anaerobic microbial iron oxidation and reduction. Nat. Rev. Microbiol. 4, $752-764$.

Weber, K.A., Urrutia, M.M., Churchill, P.F., Kukkadapu, R.K., Roden, E.E., 2006b. Anaerobic redox cycling of iron by freshwater sediment microorganisms. Environ. Microbiol. 8, 100-113.

Westerhoff, P., James, J., 2003. Nitrate removal in zero-valent iron packed columns. Water Res. 37, 1818-1830.

Xu, D., Li, Y., Song, F., Gu, T., 2013. Laboratory investigation of microbiologically influenced corrosion of C1018 carbon steel by nitrate reducing bacterium $\mathrm{Ba}$ cillus licheniformis. Corros. Sci. 77, 385-390.

Yuan, S.J., Liang, B., Zhao, Y., Pehkonen, S.O., 2013. Surface chemistry and corrosion behaviour of 304 stainless steel in simulated seawater containing inorganic sulphide and sulphate-reducing bacteria. Corros. Sci. 74, 353-366.

Zarasvand, K.A., Rai, V.R., 2014. Microorganisms: induction and inhibition of corrosion in metals. Int. Biodeterior. Biodegrad. 87, 66-74. 
Zhang, W.D., DiGiano, F.A., 2002. Comparison of bacterial regrowth in distribution systems using free chlorine and chloramine: a statistical study of causative factors. Water Res. 36, 1469-1482.

Zhang, Y., Edwards, M., 2007. Anticipating effects of water quality changes on iron corrosion and red water. J. Water Supply Res. Technol.-AQUA 56, 55-68.
Zhang, Y., Griffin, A., Edwards, M., 2008. Nitrification in premise plumbing: role of phosphate, pH and pipe corrosion. Environ. Sci. Technol. 42, 4280-4284.

Zhu, Y., Wang, H.B., Li, X.X., Hu, C., Yang, M., Qu, J.H., 2014. Characterization of biofilm and corrosion of cast iron pipes in drinking water distribution system with $\mathrm{UV} / \mathrm{Cl}_{2}$ disinfection. Water Res. 60, 174-181. 